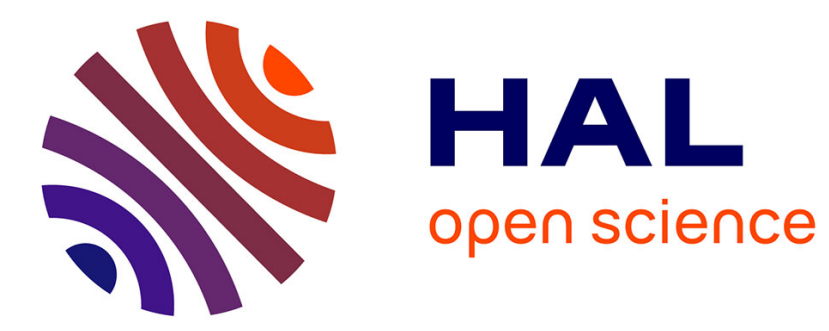

\title{
A comparative study of fatigue behaviour of flax/epoxy and glass/epoxy composites
}

\author{
Shaoxiong Liang, Papa-Birame Gning, Laurent Guillaumat
}

\section{To cite this version:}

Shaoxiong Liang, Papa-Birame Gning, Laurent Guillaumat. A comparative study of fatigue behaviour of flax/epoxy and glass/epoxy composites. Composites Science and Technology, 2012, 72 (5), pp.535543. 10.1016/j.compscitech.2012.01.011 . hal-01089436

\section{HAL Id: hal-01089436 https://hal.science/hal-01089436}

Submitted on 1 Dec 2014

HAL is a multi-disciplinary open access archive for the deposit and dissemination of scientific research documents, whether they are published or not. The documents may come from teaching and research institutions in France or abroad, or from public or private research centers.
L'archive ouverte pluridisciplinaire HAL, est destinée au dépôt et à la diffusion de documents scientifiques de niveau recherche, publiés ou non, émanant des établissements d'enseignement et de recherche français ou étrangers, des laboratoires publics ou privés. 


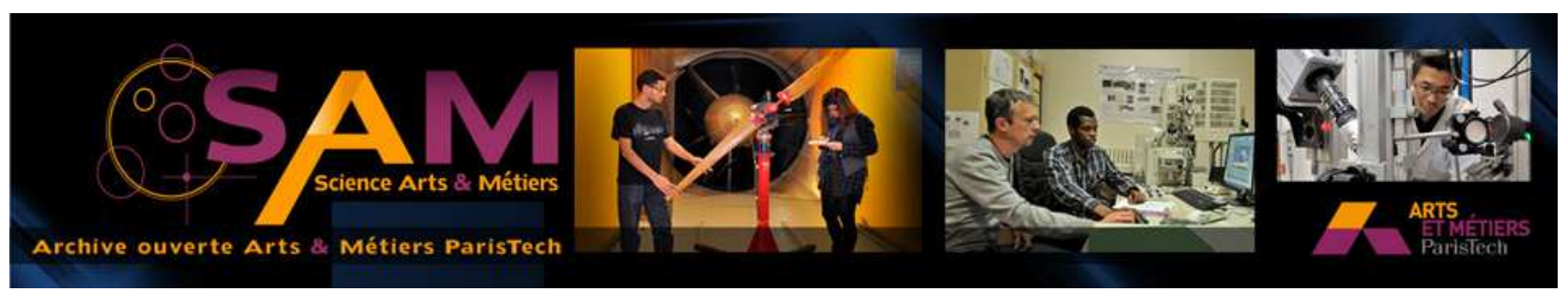

Science Arts \& Métiers (SAM)

is an open access repository that collects the work of Arts et Métiers ParisTech researchers and makes it freely available over the web where possible.

This is an author-deposited version published in: http://sam.ensam.eu

Handle ID: .http://hdl.handle.net/10985/9044

\section{To cite this version :}

Shaoxiong LIANG, Papa-Birame GNING, Laurent GUILLAUMAT - A comparative study of fatigue behaviour of flax/epoxy and glass/epoxy composites - Composites Science and Technology - Vol. $72, n^{\circ} 5$, p. $535-543-2012$ 
Review

\title{
A comparative study of fatigue behaviour of flax/epoxy and glass/epoxy composites
}

\author{
S. Liang ${ }^{\mathrm{a}, *}$, P.B. Gning ${ }^{\mathrm{a}}$, L. Guillaumat ${ }^{\mathrm{b}}$ \\ a DRIVE-ISAT, Universite de Bourgogne, 58027 Nevers, Cedex, France \\ ${ }^{\mathrm{b}}$ ENSAM, 49035 Angers, Cedex, France
}

Keywords:

Flax fibres

A. Glass fibres

A. Polymer-matrix composites (PMCs)

B. Fatigue

B. Mechanical properties

\begin{abstract}
A B S T R A C T
Experimental investigations on flax and glass fabrics reinforced epoxy specimens, i.e. FFRE and GFRE, submitted to fatigue tests are presented in this paper. Samples having $[0 / 90]_{3 S}$ and $[ \pm 45]_{3 s}$ stacking sequences, with similar fibre volume fractions have been tested under tension-tension fatigue loading. The specific stress-number of cycles to failure $(S-N)$ curves, show that for the $[0 / 90]_{3 S}$ specimens, FFRE have lower fatigue endurance than GFRE, but the $[ \pm 45]_{3 S}$ FFRE specimens offer better specific fatigue endurance than similar GFRE, in the studied life range $\left(<2 \times 10^{6}\right)$. Overall, the three-stage stiffness degradation is observed in all cases except for $[0 / 90]_{3 S}$ FFRE specimens, which present a stiffening phenomenon of around $2-3 \%$ which could be related to the straightening of the microfibrils.
\end{abstract}

\section{Contents}

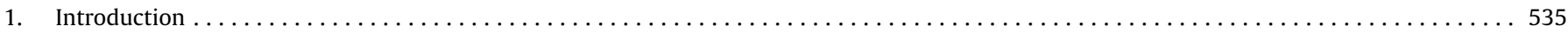

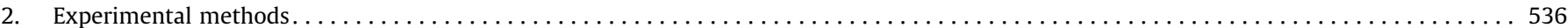

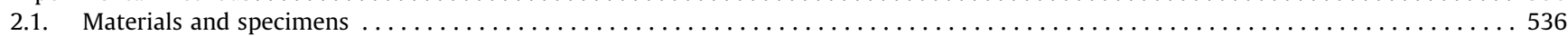

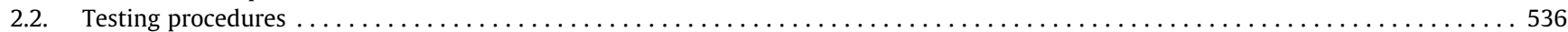

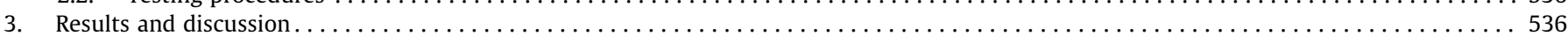

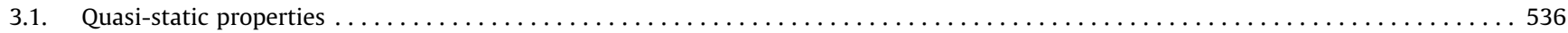

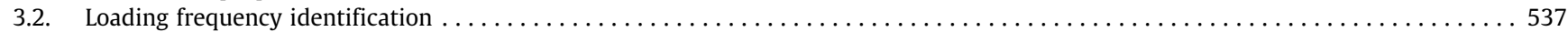

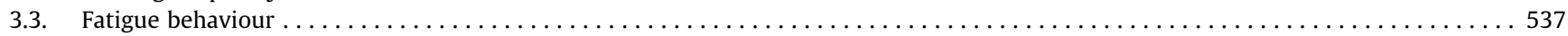

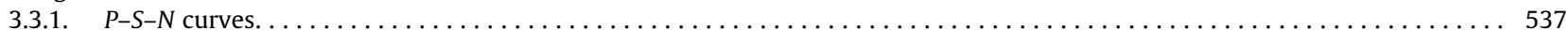

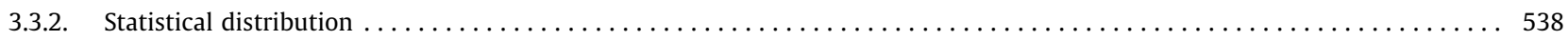

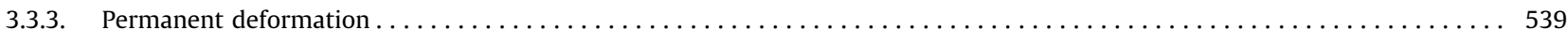

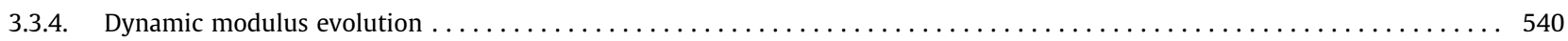

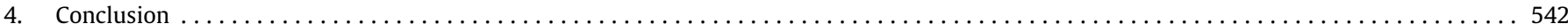

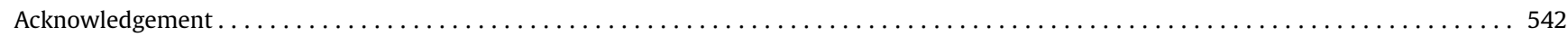

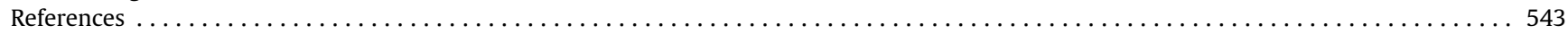

\section{Introduction}

Composite materials reinforced with synthetic fibres, particularly with glass, are widely used in industrial applications. However, the use of glass fibres reinforced polymer composites raises many occupational health and environmental issues due to the important

\footnotetext{
* Corresponding author. Tel.: +33 3867150 48; fax: +33 386715001 .

E-mail address: shaoxiong.liang@u-bourgogne.fr (S. Liang).
}

energy consumption and the emission of pollutants during the fabrication [1]. These considerations justify the introduction of natural fibres as reinforcements in composite materials because they are derived from renewable and biodegradable resources. Moreover the elaboration process is less energy intensive than that for mineral fibres manufacturing [2]. Among the available natural reinforcements, flax fibres offer interesting specific mechanical properties (divided by respective density), which are comparable to glass fibres ones [3]. Important interest of the researchers has aroused for these 
materials and has led to a consequent number of studies related to natural fibres in the past few years [1-10].

However, only a few papers related to the fatigue behaviour of natural fibre reinforcements are available. Baley [6] has highlighted the increase of the Young's modulus of flax fibres for a certain number of loading cycles. The stiffness of a single fibre can rise from $40 \mathrm{GPa}$ up to nearly $70 \mathrm{GPa}$. Placet [7] in his study concerning the thermo-mechanical behaviour of hemp fibres by means of dynamic mechanical analysis from 20 to $200{ }^{\circ} \mathrm{C}$, has reported a storage modulus increase of $60 \%$. Tong and Isaac [8] have compared the impact and fatigue behaviour of hemp fibre mat and $\pm 45^{\circ}$ glass fibre reinforced composites. Results show that, during fatigue cycling, the hemp fibre reinforced polymer fails without any prior visible effect on modulus. Silva et al. [9] have been interested in the fatigue behaviour of sisal fibres. The authors have found that at a fatigue stress below 50\% ultimate tensile strength (UTS), all tested fibres can resist more than $10^{6}$ cycles. A slight increase of the hysteresis slope, which suggests an increase on fibre's Young's modulus, has been observed. More recently, investigations on the fatigue behaviour of bio-sourced composites reinforced with natural fibres have been published by Towo and Ansell [10]. The authors have studied the effects of chemical treatments on reinforcements and matrix of unidirectional (UD) sisal fibre impregnated with epoxy and polyester matrix. Composites reinforced with $\mathrm{NaOH}$ treated fibre exhibit a slight improvement on the laminates' fatigue resistance. Moderate raise of the composites' initial rigidity has been observed in the tension-tension fatigue test.

Despite of the great interest on biocomposite materials as alternative composites, a limited number of studies have focused on their fatigue response. This paper presents an experimental study on the fatigue behaviours of flax fibre reinforced epoxy (FFRE). In order to evaluate the benefits of this material, comparable glass fibre reinforced epoxy (GFRE) have also been tested under fatigue loading.

\section{Experimental methods}

\subsection{Materials and specimens}

FFRE and GFRE specimens were made of commercial dry rollers of non-crimp flax and E-glass fabrics, with areal weights of 235 and $434 \mathrm{~g} / \mathrm{m}^{2}$, respectively. The balanced fabrics consisted of two identical layers of UD fibres oriented perpendicular to each other and stitched together by a cotton thread of $2 \mathrm{~g} / \mathrm{m}^{2}$ for flax and by a polyester thread of $6 \mathrm{~g} / \mathrm{m}^{2}$ (Fig. 1). Flax and glass fabrics have been supplied by CRST, a local textile company and by SAERTEX, respectively. Both fabrics were used as received. The matrix was an epoxy system based on the resin SR 8200 with SR 8205 hardener from SICOMIN.Fibre layers were first cut from the roller and manually impregnated with the liquid matrix. The plies were hand-laid, before they were stacked under pressure in a hydraulic press equipped with heating plates. The assembly was heated at a rate of $2{ }^{\circ} \mathrm{C} / \mathrm{min}$ up to a constant temperature of $60^{\circ} \mathrm{C}$ for $8 \mathrm{~h}$. The process pressures were 7 and 2 bars for FFRE and GFRE, respectively. The difference of pressures permitted to ensure similar fibre volume fractions $\left(V_{f}\right)$ for the two materials (Table 1$)$. Because of material properties of composites depend mainly on the fibre volume fraction [4], one can suppose that the 5 bar difference in curing pressure does not affect the mechanical properties. However, a difference in void fraction $\left(V_{v}\right)$ is noticeable. The cooling of the moulded plate was realized at room temperature. Two stacking sequences of composite, i.e. $[0 / 90]_{3 S}$ and $[ \pm 45]_{3 S}$, were fabricated for quasi-static tensile and fatigue tests.The laminates' thickness $(t)$, densities $\left(\rho_{c}\right)$, fibre volume fraction, and volume fraction of void are given in Table 1 with the standard deviations (SD) in brackets. $V_{f}$ was calculated according to ASTM standard [11] using the

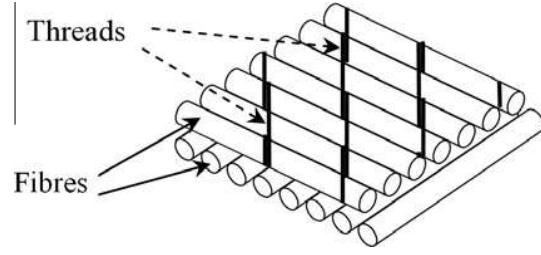

Fig. 1. Structure of the non-crimp fabric.

calculation method. Considering the variations of the fibre fractions of the two composites, it was assumed that the $V_{f}$ are equivalent. The void fraction of FFRE is smaller because of the higher pressure process used ( 7 bars).

Rectangularly shaped specimens with a length and width of $250 \mathrm{~mm}$ and $25 \mathrm{~mm}$ were cut from the laminated plates with a high speed rotating abrasive disk. No lubrication fluid was used during cutting of FFRE specimens to avoid moisture absorption. After cutting, the edges were slightly polished with fine sandpaper. All specimens were equipped with $50 \mathrm{~mm}$ long and $3 \mathrm{~mm}$ thick aluminium end-tabs, leaving the specimens' gauge length of $150 \mathrm{~mm}$.

\subsection{Testing procedures}

In order to determine the ultimate strength, quasi-static tensile tests, according to the ISO 527-4 standard, have been performed on $[0 / 90]_{3 S}$ and $[ \pm 45]_{3 S}$ specimens. Five replicates have been tested in each sample. Specimens were equipped with strain gauge rosettes consisting of two grids of $5 \mathrm{~mm}$ provided from KYOWA. The testing machine used, for all static and dynamic loading tests, was a servohydraulic MTS 809 with a capacity of $100 \mathrm{kN}$. The crosshead speed was $2 \mathrm{~mm} / \mathrm{min}$. In order to limit the testing temperature to $23^{\circ} \mathrm{C}$, the tests have been carried out in a Servathin thermal chamber.

Tension-tension fatigue tests, under load amplitude control with a loading ratio of $R=0.1$ have been conducted on FFRE and GFRE specimens with identical testing conditions to quasi-static tests. According to ISO 13003 standard [12], the recommended loading frequency $(f)$ should ensure a self-heating of specimens $(\Delta T)$ of less than $10^{\circ} \mathrm{C}$ during the test. Doehlert $[13,14]$ experimental design program with seven tests on FFRE specimens has been used to establish second order response surface of $\Delta T$, as detailed in [4]. The chosen ranges of the parameters, i.e. loading frequency (f) and loading level were from 2 to $14 \mathrm{~Hz}$ and from 0.4 to $0.8 \mathrm{UTS}$, respectively. The test temperatures have been recorded via a ThermaCAM SC3000 infrared camera. Results discussed in Section 3.2 show that a $5 \mathrm{~Hz}$ testing frequency is a good compromise between the experimental time consumption and the conformance with the fatigue standard.

Five loading levels ranging from 0.4 to 0.8 UTS have been tested. Tweleve replicate tests have been performed at each stress level for FFRE. In order to compare the FFRE and GFRE fatigue behaviours, five GFRE specimens have been tested at each loading level. Tests have been stopped at specimens' failure or at $2 \times 10^{6}$ cycles.

The MTS 809 testing machine was equipped with a crosshead displacement sensor $(\Delta l)$, with a $0.003 \mathrm{~mm}$ resolution corresponding to a strain precision $\left(\Delta l / l_{0}\right)$ of $0.002 \%$ for the gauge length of specimens $l_{0}=150 \mathrm{~mm}$. It was assumed that such an accuracy of the strain data is satisfactory for this study. Therefore, the strains in the fatigue tests have been calculated based on the ratio of the crosshead displacements to the specimen gauge length.

\section{Results and discussion}

\subsection{Quasi-static properties}

The representative loading curves of $[0 / 90]_{3 S}$ and $[ \pm 45]_{3 S}$ FFRE and GFRE specimens, are presented in Fig. 2. It can be seen that 
the GFRE exhibit better performance than the FFRE for both stacking sequences. Elastic properties, e.g. Young's modulus $(E)$ and Poisson's ratio $(v)$ measured in the strain range of $0.05-0.25 \%$ as well as the tensile strength ( $\left.\sigma_{\text {UTS }}\right)$ and ultimate strain $\left(\varepsilon_{\text {UTS }}\right)$ data are presented in Table 2 . The coefficients of variation (CV) in percentage are given in brackets. For $[0 / 90]_{3 S}$ specimens, the modulus and the strength of FFRE are respectively 35\% and 55\% lower than the corresponding properties for GFRE. Also, the properties of the FFRE $[ \pm 45]_{3 S}$ specimens are $41 \%$ and $23 \%$ lower. This observation is due to the higher intrinsic mechanical properties of the glass fibre compared to flax. One can remark that the CV of the FFRE is much lower than that of flax fibres [5] because of the averaging effect on the composite scale. The scattering of the two materials is comparable.

\subsection{Loading frequency identification}

The effect of the loading frequency has been studied by measurement of samples' self-heating temperature in the central area. Generally, $\Delta T$ rises at the early stage of the test and stabilizes after around $500 \mathrm{~s}$ as plotted in Fig. 3.Fringe plots (Fig. 4) show that $\Delta T$ increases with loading level and testing frequency. Results show that, by strictly following the standard $[12]\left(\Delta T<10^{\circ} \mathrm{C}\right)$, the testing frequency should not exceed $8 \mathrm{~Hz}$ and $2.5 \mathrm{~Hz}$ for $[0 / 90]_{3 \mathrm{~s}}$ and $[ \pm 45]_{35}$ FFRE specimens, respectively. However, due to the high number of tests foreseen, a higher test frequency is desired. $5 \mathrm{~Hz}$ appeared as a good compromise ensuring the recommended selfheating for all specimens, except for $[ \pm 45]_{35}$ samples tested at 0.8 UTS. Moreover, three $[ \pm 45]_{3 S}$ FFRE specimens tested at $1 \mathrm{~Hz}$ and $0.8 \mathrm{UTS}$, exhibited $\Delta T=7.4^{\circ} \mathrm{C}$ with an average life equivalent to $5 \mathrm{~Hz}$ tested specimens.

\subsection{Fatigue behaviour}

\subsection{1. $P-S-N$ curves}

Table 3 gives the average fatigue life $\left(N_{f}^{a v g}\right)$ with the average logarithm of the specimens' number of cycles to failure $\left(\log \left(N_{f}\right)^{a v g}\right)$. The standard deviation for each loading level of FFRE and GFRE specimens is also given. Corresponding experimental results are plotted in Figs. 5a and 6a. A modified $S-N$ curve function (Eq. (1)) is used to model specimens' life. $y$ is the maximum loading stress in MPa plotted as ordinate, while the abscissa value $x$ is expressed in Eq. (2). $N_{f}$ is the number of cycles to failure, $A$ and $B$ are intrinsic parameters of the material, and $C$ represents the number of standard deviation ( $s$ ) corresponding to the confidence level [15]. $s$ is calculated under the hypothesis of a constant standard deviation throughout all loading levels. The identified parameters of Eq. (1) are given in Table 4 . $C$ equal to 0 and -2 correspond

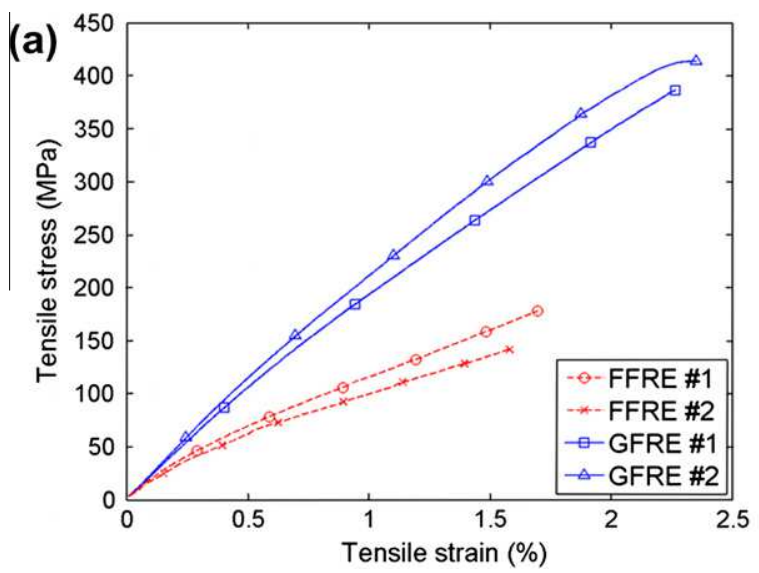

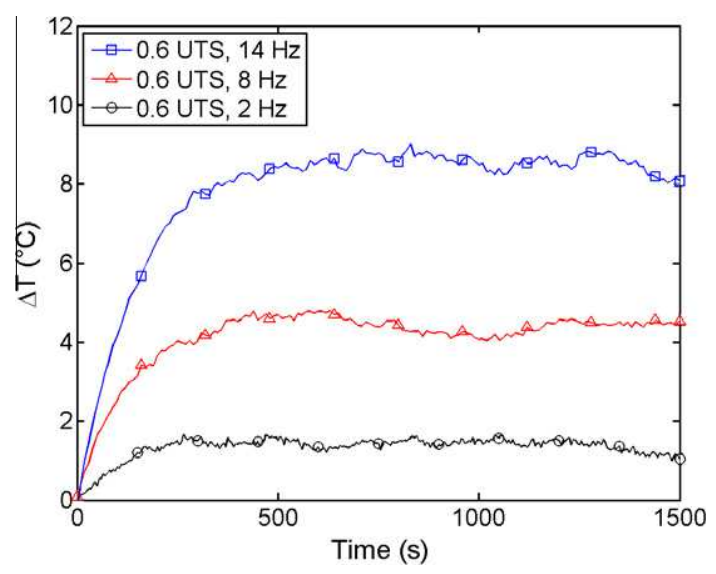

Fig. 3. Temperature arising kinetic of $[ \pm 45]_{3 S}$ FFRE specimens.

respectively to curve with $50 \%$ and of $98 \%$ of survival probability for all studied materials.

The stress-number of cycles to failure curves for different confidence levels e.g. survival probabilities of $50 \%$ and $98 \%,(P-S-N)$ of $[0 / 90]_{3 S}$ specimens are plotted in Fig. 5 a. The regression coefficient $(r)$ of $S-N$ curves for the FFRE and GFRE samples are -0.947 and -0.972 , respectively, indicating that the model fits well with the data points. The two curves reveal that the GFRE specimens exhibit a higher resistance to fatigue loading in the studied ranges. This is in accordance with the higher static strength of the glass reinforced composite. At the fixed endurance limit of $2 \times 10^{6} \mathrm{cy}-$ cles, an increase of confidence from $50 \%$ to $98 \%$ reduces the design stress by $27.1 \%$ and $26.4 \%$ for FFRE and GFRE, respectively. However, the higher static strength becomes less preeminent as the imposed cyclic stress decreases. The slope of the GFRE curve is steeper $(B=56.5)$ than that of the FFRE $(B=25.2)$, implying a more important decrease of the stress level with respect to the fatigue life. The evolution of the specific stress $(\bar{\sigma})$ which is the ratio of the applied stress and the composite's densities given in Table 1, as a function of $\log \left(N_{f}\right)$ is plotted in Fig. $5 \mathrm{~b}$. One can see that the difference of FFRE and GFRE is reduced, and for $\bar{\sigma}=88 \mathrm{MPa}$ the experimental points of the two composites coincide at around $10^{5}$ cycles.

$y=A-B x+C s$

$x=\log \left(N_{f}\right)$

The $P-S-N$ curves of $[ \pm 45]_{3 S}$ specimens are plotted in Fig. $6 a$. All samples tested at 0.4 and 0.5 UTS (represented by points with

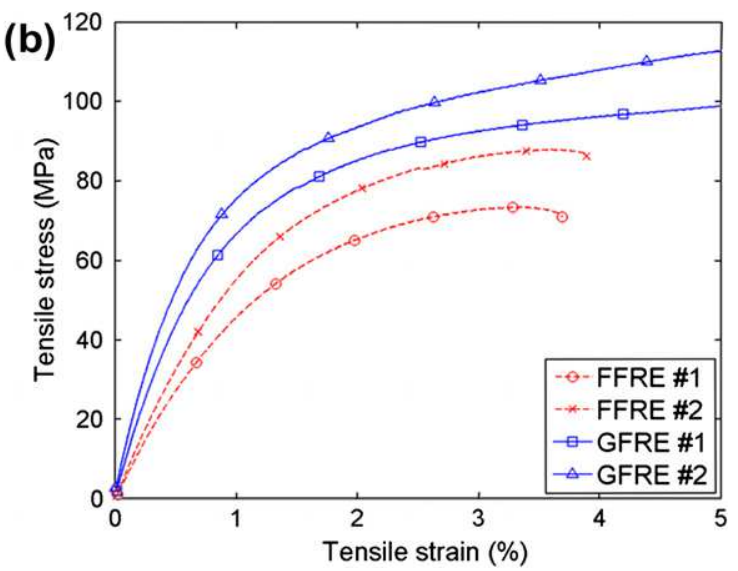

Fig. 2. Quasi-static responses in tensile loading of (a) $[0 / 90]_{3 s}$ and (b) $[ \pm 45]_{3 s}$ for FFRE and GFRE specimens. 

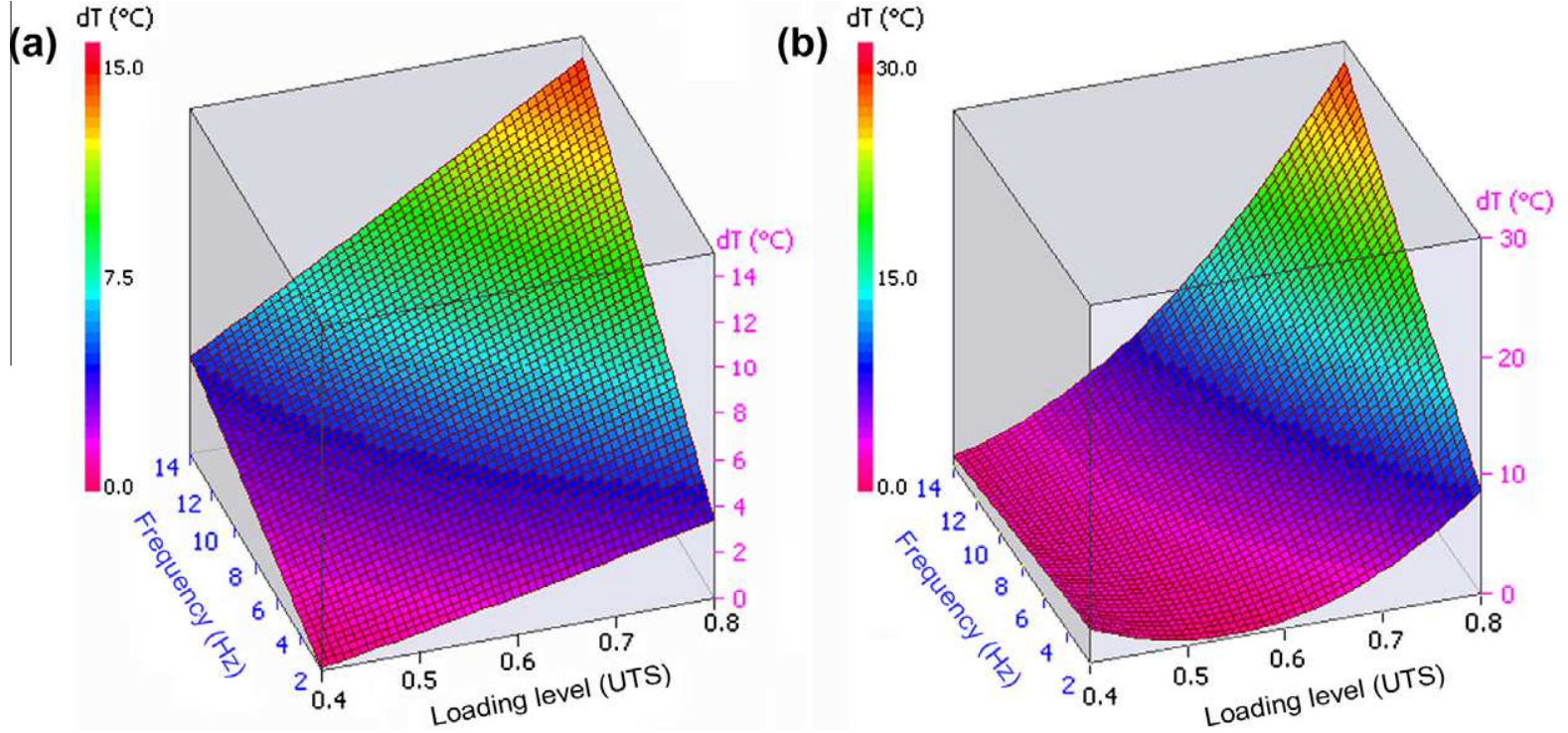

Fig. 4. Temperature response plots of (a) $[0 / 90]_{3 S}$ and (b) $[ \pm 45]_{3 S}$ FFRE specimens.

Table 1

Average physical properties of FFRE and GFRE composites; standard deviations in brackets.

\begin{tabular}{lllll}
\hline & $t(\mathrm{~mm})$ & $\rho_{c}\left(\mathrm{~g} / \mathrm{cm}^{3}\right)$ & $V_{f}(\%)$ & $V_{v}(\%)$ \\
\hline FFRE $\left((0 / 90)_{3 \mathrm{~S}}\right.$ and $\left.( \pm 45)_{3 \mathrm{~S}}\right)$ & $2.18(0.07)$ & $1.28(0.01)$ & $43.7(1.5)$ & $1.3(0.8)$ \\
GFRE $\left((0 / 90)_{3 \mathrm{~S}}\right.$ and $\left.( \pm 45)_{3 \mathrm{~S}}\right)$ & $2.33(0.04)$ & $1.79(0.03)$ & $42.5(1.0)$ & $3.8(2.0)$ \\
\hline
\end{tabular}

Table 2

Average in-plane mechanical properties of FFRE and GFRE laminates; coefficients of variation in \% in brackets.

\begin{tabular}{lllll}
\hline & $E(\mathrm{GPa})$ & $v$ & $\sigma_{U T S}(\mathrm{MPa})$ & $\varepsilon_{U T S}(\%)$ \\
\hline FFRE $(0 / 90)_{3 S}$ & $14.3(5.5 \%)$ & $0.17(28 \%)$ & $170(11.5 \%)$ & $1.72(7.6 \%)$ \\
GFRE $(0 / 90)_{3 S}$ & $21.9(5.1 \%)$ & $0.14(3.0 \%)$ & $380(6.8 \%)$ & $2.16(7.3 \%)$ \\
FFRE $( \pm 45)_{3 S}$ & $6.5(10.1 \%)$ & $0.75(4.7 \%)$ & $79(8.3 \%)$ & $3.8(16 \%)$ \\
GFRE $( \pm 45)_{3 S}$ & $11.1(9.6 \%)$ & $0.48(17 \%)$ & $103(8.1 \%)$ & $>5$ \\
\hline
\end{tabular}

arrows) did not break before the endurance limit defined at $2 \times 10^{6}$ cycles. $S-N$ curves according to Eq. (1) with $50 \%$ and $98 \%$ survival probability for both composites are plotted. For this stacking sequence, the regression coefficients $(r)$ for FFRE and GFRE samples are -0.938 and -0.960 , respectively, is satisfactory. GFRE specimens present better fatigue resistance at higher loading levels. The $50 \% S-N$ curves intersect at $\log (N)=3.73$ (5370 cycles) and $\sigma=64 \mathrm{MPa}$. Below this stress, the fatigue behaviour of both laminates can be considered to be comparable. The specific $S-N$ diagrams plotted in Fig. 6b reveal that the FFRE composite has a better fatigue resistance in the studied range.

It can be noted that the fatigue curves normalised by the tensile strength (Table 3) reveal the predominance of the FFRE specimens on GFRE for both stacking sequences. Also, the difference in voids fraction (Table 3) can possibly influence fatigue behaviour of specimens. This needs further investigations to be verified.

\subsubsection{Statistical distribution}

In the previous section, the $P-S-N$ curves have been plotted with the assumption that the life of the specimens $\left(\log \left(N_{f}\right)\right)$ follows a normal distribution and that the SD is constant for all loading levels, as mentioned in the statistical treatment standard [15]. This standard refers to the fatigue of metallic materials. This section is dedicated to the verification of this hypothesis for the FFRE specimens. The cumulative survival probability $\left(F w_{\exp }\right)$ of $[0 / 90]_{3 S}$ and $[ \pm 45]_{3 S}$ specimens and the normal cumulative distribution fitting curves $(F w(x))$ are compared in Fig. 7. $F w_{\text {exp }}$ in each loading level has been calculated from Eq. (3), where $Q$ is the total number of tested specimens and $i$ is the decreasing order of the fatigue life data. The cumulative normal distribution curve is given in Eq. (4), where $x=\log \left(N_{f}\right), \mu$ and $s$ are the average specimen life and SD for each loading level. Based on Chi-square normal distribution test, $\chi^{2}$ varied from 0.310 to 5.57 , corresponding to $\chi_{005}^{2}$ and $\chi_{75}^{2}$, the hypothesis of the normal distribution of $\log \left(N_{f}\right)$ is considered to be validated.

Table 3

Average fatigue life of FFRE and GFRE specimens; standard deviations in brackets.

\begin{tabular}{|c|c|c|c|c|c|c|c|c|c|c|}
\hline & \multicolumn{2}{|l|}{0.8 UTS } & \multicolumn{2}{|l|}{0.7 UTS } & \multicolumn{2}{|l|}{0.6 UTS } & \multicolumn{2}{|l|}{0.5 UTS } & \multicolumn{2}{|l|}{0.4 UTS } \\
\hline & $N_{f}^{a v g}$ & $\log \left(N_{f}\right)^{a v g}$ & $N_{f}^{a v g}$ & $\log \left(N_{f}\right)^{a v g}$ & $N_{f}^{a v g}$ & $\log \left(N_{f}\right)^{a v g}$ & $N_{f}^{a v g}$ & $\log \left(N_{f}\right)^{a v g}$ & $N_{f}^{a v g}$ & $\log \left(N_{f}\right)^{a v g}$ \\
\hline $\begin{array}{l}\text { FFRE } \\
\qquad(0 / 90)_{3 S}\end{array}$ & $\begin{array}{l}2058 \\
(1485)\end{array}$ & $\begin{array}{l}3.16 \\
(0.43)\end{array}$ & $\begin{array}{l}12710 \\
(9483)\end{array}$ & $\begin{array}{l}4.00 \\
(0.33)\end{array}$ & $\begin{array}{l}79183 \\
(74017)\end{array}$ & $\begin{array}{l}4.80 \\
(0.28)\end{array}$ & $\begin{array}{l}206666 \\
(114849)\end{array}$ & $\begin{array}{l}5.24 \\
(0.27)\end{array}$ & $\begin{array}{l}1151224 \\
(481840)\end{array}$ & $\begin{array}{l}6.12 \\
(0.19)\end{array}$ \\
\hline $\begin{array}{l}\text { GFRE } \\
\qquad(0 / 90)_{3 \mathrm{~S}}\end{array}$ & $\begin{array}{l}665 \\
(330)\end{array}$ & $\begin{array}{l}2.79 \\
(0.18)\end{array}$ & $\begin{array}{l}2541 \\
(875)\end{array}$ & $\begin{array}{l}3.39 \\
(0.14)\end{array}$ & $\begin{array}{l}11076 \\
(6833)\end{array}$ & $\begin{array}{l}3.98 \\
(0.24)\end{array}$ & $\begin{array}{l}72153 \\
(55035)\end{array}$ & $\begin{array}{l}4.76 \\
(0.33)\end{array}$ & $\begin{array}{l}353871 \\
(229543)\end{array}$ & $\begin{array}{l}5.47 \\
(0.30)\end{array}$ \\
\hline $\begin{array}{l}\text { FFRE } \\
\qquad( \pm 45)_{3 \mathrm{~S}}\end{array}$ & $\begin{array}{l}4308 \\
(3012)\end{array}$ & $\begin{array}{l}3.50 \\
(0.40)\end{array}$ & $\begin{array}{l}37308 \\
(24282)\end{array}$ & $\begin{array}{l}4.40 \\
(0.27)\end{array}$ & $\begin{array}{l}438617 \\
(288223)\end{array}$ & $\begin{array}{l}5.57 \\
(0.25)\end{array}$ & $>2 \times 10^{6}$ & $>6.30$ & $>2 \times 10^{6}$ & $>6.30$ \\
\hline $\begin{array}{l}\text { GFRE } \\
\qquad( \pm 45)_{3 \mathrm{~S}}\end{array}$ & $\begin{array}{l}700 \\
(185)\end{array}$ & $\begin{array}{l}2.90 \\
(0.04)\end{array}$ & $\begin{array}{l}1790 \\
(350)\end{array}$ & $\begin{array}{l}3.25 \\
(0.08)\end{array}$ & $\begin{array}{l}7771 \\
(2874)\end{array}$ & $\begin{array}{l}3.87 \\
(0.16)\end{array}$ & $>2 \times 10^{6}$ & $>6.30$ & $>2 \times 10^{6}$ & $>6.30$ \\
\hline
\end{tabular}



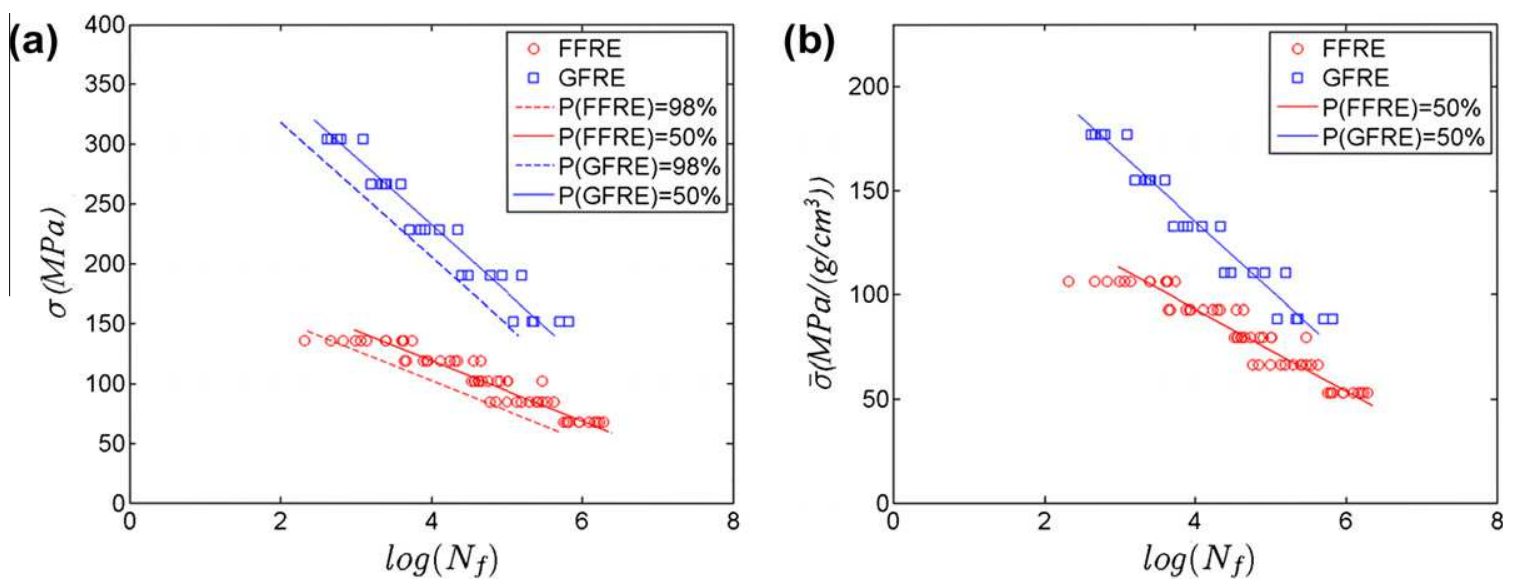

Fig. 5. $P-S-N\left(\right.$ a) and specific $S-N$ (b) behaviour of $[0 / 90]_{3 S}$ FFRE and GFRE specimens.
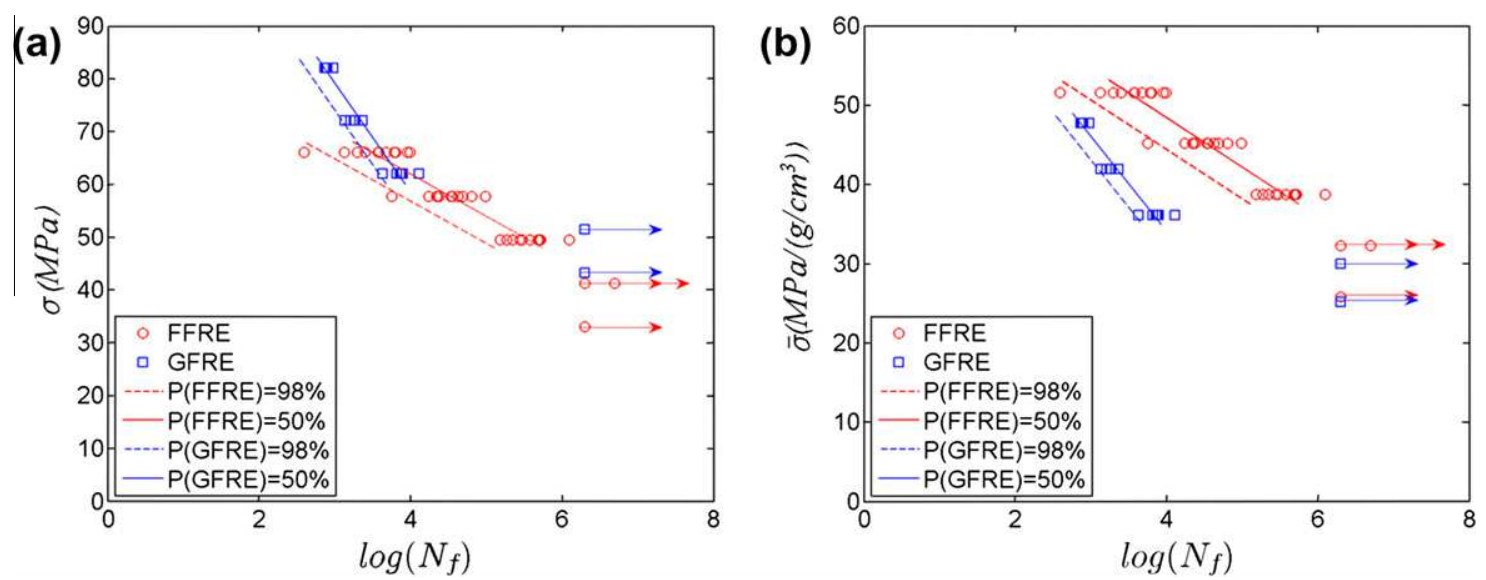

Fig. 6. $S-N\left(\right.$ a) and specific $S-N\left(\right.$ b) behaviour of $[ \pm 45]_{3 S}$ FFRE and GFRE specimens.

Table 4

S-N curve parameters.

\begin{tabular}{llrr}
\hline & $A$ & \multicolumn{1}{c}{$B$} & \multicolumn{1}{c}{$s$} \\
\hline FFRE $(0 / 90)_{3 S}$ & 220 & 25.2 & 8.3 \\
GFRE $(0 / 90)_{3 S}$ & 459 & 56.5 & 13.6 \\
FFRE $( \pm 45)_{3 S}$ & 94 & 7.0 & 2.6 \\
GFRE $( \pm 45)_{3 S}$ & 141 & 20.6 & 2.6
\end{tabular}

$F w_{\exp }=i /(Q+1)$

$F w(x)=\int_{-\infty}^{x} 1 / \sqrt{2 \pi s^{2}} \times \operatorname{Exp}\left(-(x-\mu)^{2} /\left(2 s^{2}\right)\right) d x$

The standard deviations of specimens' loglife (Table 3) of each loading level are compared in Fig. 8. The scattering of the FFRE samples decreases with the decreasing loading level, which is contrary to the GFRE samples for both laminations and also to the literature review for other materials [16,17]. The hypothesis of constant SD throughout $S-N$ curve as suggested in the standard [15] is questionable for flax and glass reinforced composites.

\subsubsection{Permanent deformation}

Typical stress-strain hysteresis loops of the early $\left(n / N_{f}=0\right)$ and last loading cycles $\left(n / N_{f}=1\right)$ of the different laminates are presented in Fig. 9. Generally, the loops move towards higher strains for constant stress level. It is seen in Fig. 9b that the final hysteresis loop of the GFRE specimen moved very far from the first cycle. This difference is in accordance with the important quasistatic maximum strain data of GFRE samples (Table 2). The plot of the maximum $\left(\varepsilon_{\max }\right)$ and minimum $\left(\varepsilon_{\min }\right)$ strains with respect to the life ratio (Fig. 10) highlights a continuous increase independent of the laminates' lay-ups and reinforcement types. This is supposed to be related to the cyclic creep effect because the fatigue loading consists of a positive mean stress superimposed with sinusoidal variations $[18,21,22]$. Because both extreme strains present similar trends, only the minimum strain, indicating the permanent deformation of the samples during the test [20], is discussed subsequently. The overall development of $\varepsilon_{\text {min }}$ for all loading levels is plotted in Fig. 11. Each curve is a representative test result for a given loading condition (not an average curve) and the scattering bars enclose all the curves of the specimens tested on the same loading level. One can observe that, after a rapid rise, $\varepsilon_{\min }$ evolves into a quasi-linear stage for a long life ratio followed by an acceleration phase, except for the $[0 / 90]_{3 S}$ FFRE specimens (Fig. 11a). In this particular case, only the first two stages are observed suggesting a brittle behaviour. The more pronounced acceleration stage of the $[ \pm 45]_{3 S}$ GFRE specimens (Fig. 11d) reveals a ductile behaviour as indicated by the quasi-static failure strain (Table 2 ).

The trends of $\varepsilon_{\min }$ are similar regardless of the loading level. For a given laminate, $\varepsilon_{\min }$ increases with the imposed load. For $[0 / 90]_{35}$ specimens (Fig. 11a and b), the response curves of different loading 

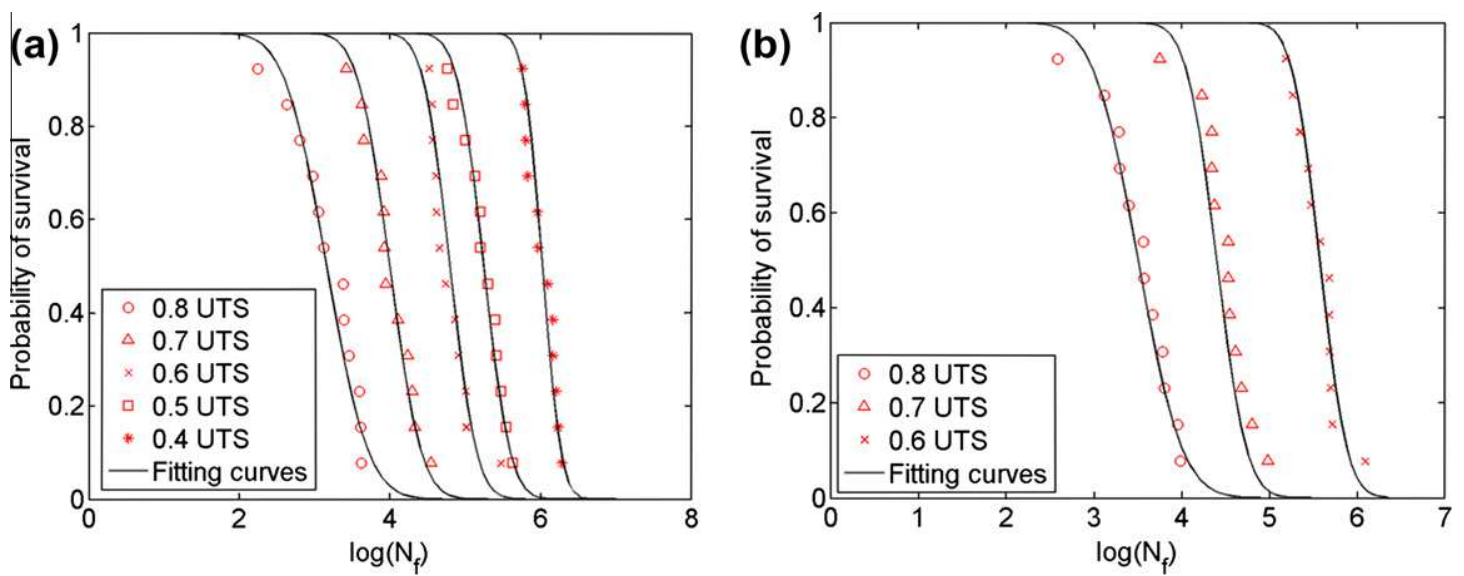

Fig. 7. Probability of survival graphs for (a) $[0 / 90]_{3 S}$ and (b) $[ \pm 45]_{3 S}$ FFRE specimens.
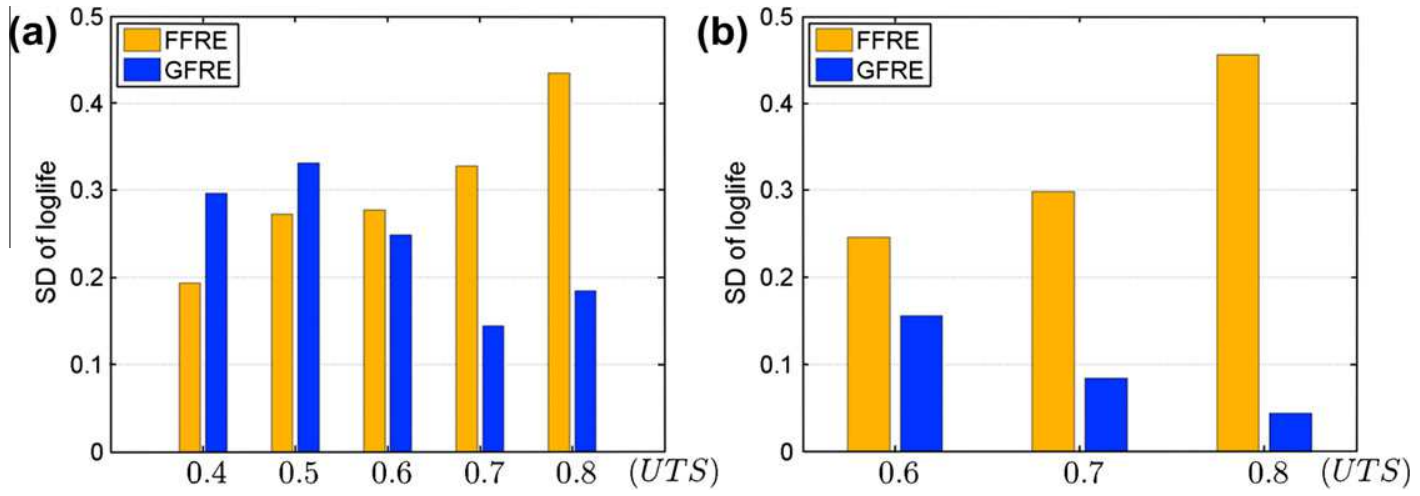

Fig. 8. Standard deviations of $\log \left(N_{f}\right)$ for (a) $[0 / 90]_{3 S}$ and (b) $[ \pm 45]_{3 S}$ FFRE and GFRE specimens.
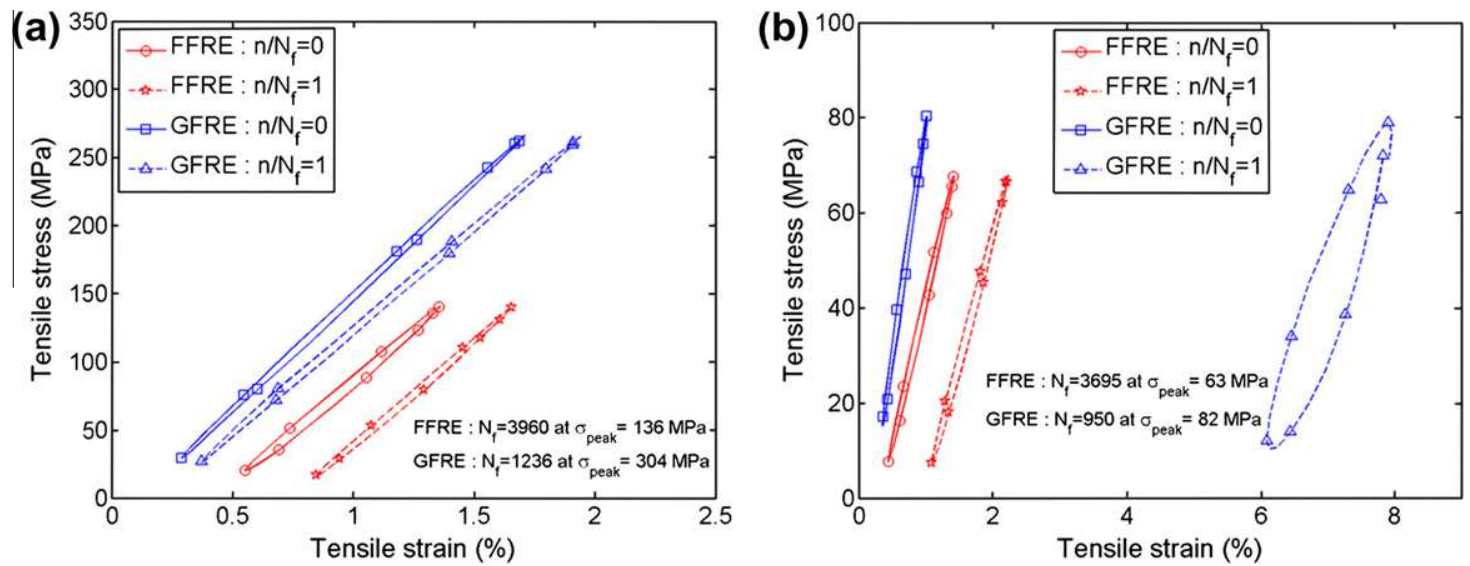

Fig. 9. First and final hysteresis loops of (a) $[0 / 90]_{3 S}$ and (b) $[ \pm 45]_{3 S}$ FFRE and GFRE specimens at 0.8 UTS.

levels seems parallel to each other, although the $N_{f}$ can have $10^{3}$ times different (Table 3). By contrast with $[0 / 90]_{35}$, the slopes of $[ \pm 45]_{3 \mathrm{~S}}$ curves increase with the loading level (Fig. 11c and d).

\subsubsection{Dynamic modulus evolution}

The evolution of the specimens' dynamic modulus gives information on the material's damage evolution. This modulus is calculated as the slope of the straight line connecting the maximum and minimum stress tips of a hysteresis loop. Fig. 12 shows typical and global evolutions of the normalized modulus $\left(E / E_{0}\right)$ with respect to the specimens life ratio for $[0 / 90]_{3 s}$ specimens, where $E$ and $E_{0}$ are respectively the actual cyclic and average modulus measured during the first cycles. As expected, the modulus of GFRE decreases in three stages: a first and third stage with a sharp decrease of the modulus and a second steady stage between the two. The loss of modulus is measured between $7 \%$ and $25 \%$. This range is similar to the general behaviour of traditional composites loaded in fatigue as described by Case and Reifsnider [17]. The overall evolution of GFRE plotted in Fig. 12b shows that this evolution depends on the loading level, i.e. more stiffness loss is recorded for lower loadings. 

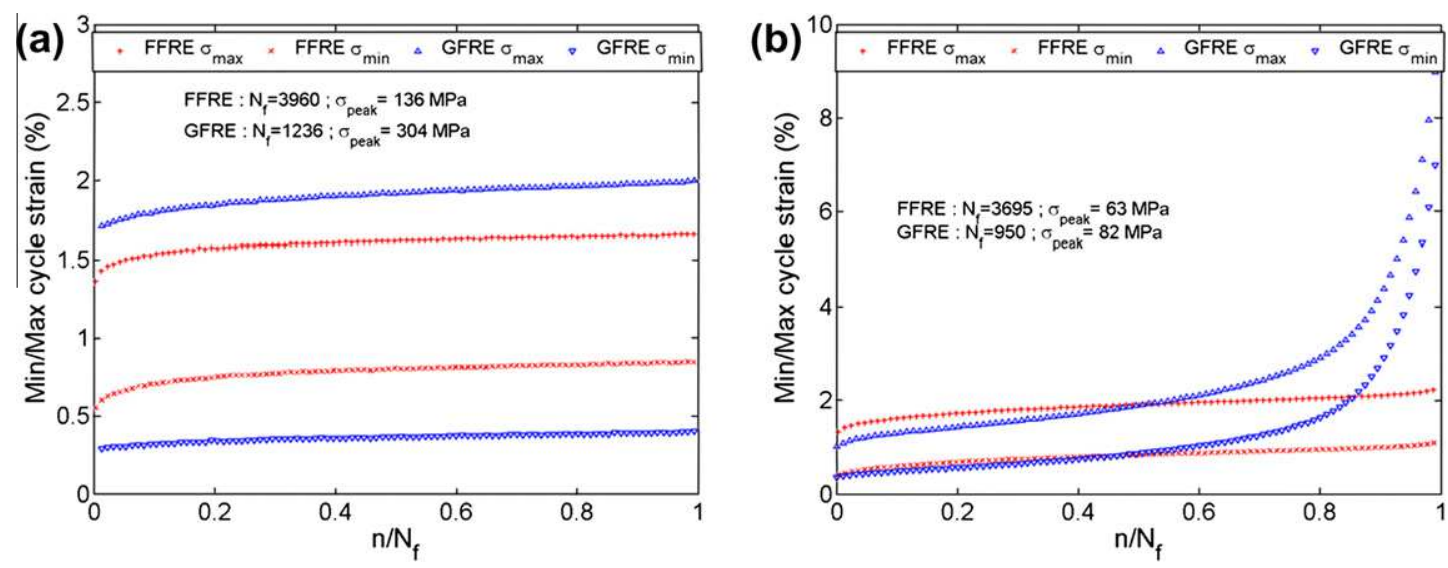

Fig. 10. Typical maximum and minimum cycle strains evolution of (a) $[0 / 90]_{3 S}$ and (b) $[ \pm 45]_{3 S}$ FFRE and GFRE specimens at 0.8 UTS.
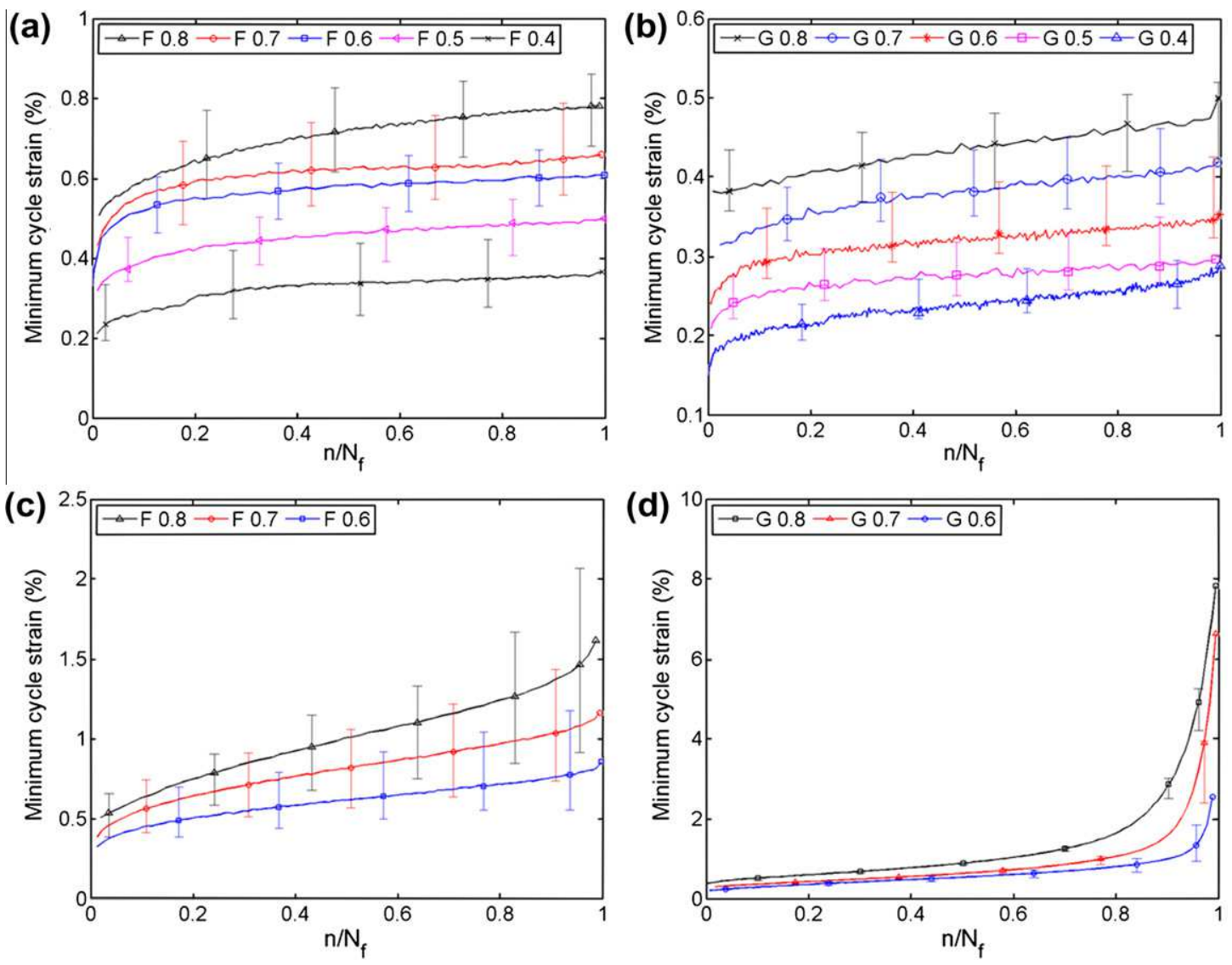

Fig. 11. Global minimum cycle strain of specimens: (a) [0/90 $]_{3 S}$ FFRE (F), (b) $[0 / 90]_{3 S}$ GFRE (G), (c) $[ \pm 45]_{3 S}$ FFRE and (d) $[ \pm 45]_{3 S}$ GFRE, for loading from 0.4 to 0.8 UTS.

In contrast, the modulus of the FFRE specimens increases by around $2 \%$ on average, with the life ratio, and then remains stable until failure without a third stiffness decreasing stage (Fig. 12a). From Fig. 12b, it can be concluded that the evolution of the scattering of specimens tested on the same loading level (conditions) is independent of the loading level.

For some conventional composites materials, a stiffening effect is noticed due to the annealing effect of the polymer matrix [19]. However, in the present study, laminates were made of the same epoxy matrix with an identical curing process, but the enhancement phenomenon is observed only in the specimens reinforced with flax fibres with $[0 / 90]_{3 s}$ layup. Indeed, the tensile modulus increase of single natural fibres in cyclic loading (e.g. flax, sisal, hemp) has been described in [6,7,9]. Particularly, Baley [6] found that cellulose microfibrils which are spirally wound with a certain angle relative to the fibre axis, tend to straighten when the fibre is axially loaded, resulting in an important increase (60-80\%) of Young's modulus. Though, for the $[0 / 90]_{3 S}$ FFRE specimens, half of the reinforcement was loaded along the fibre axis, the rearrangement of microfibrils is responsible of the increase of the composite's modulus as depicted in [10]. In addition, even after the combing process, natural fibres of dry fabrics are not straight. Hence, during fatigue loading, the realignment of the wavy fibres can also contribute to the stiffening effect measured. These 

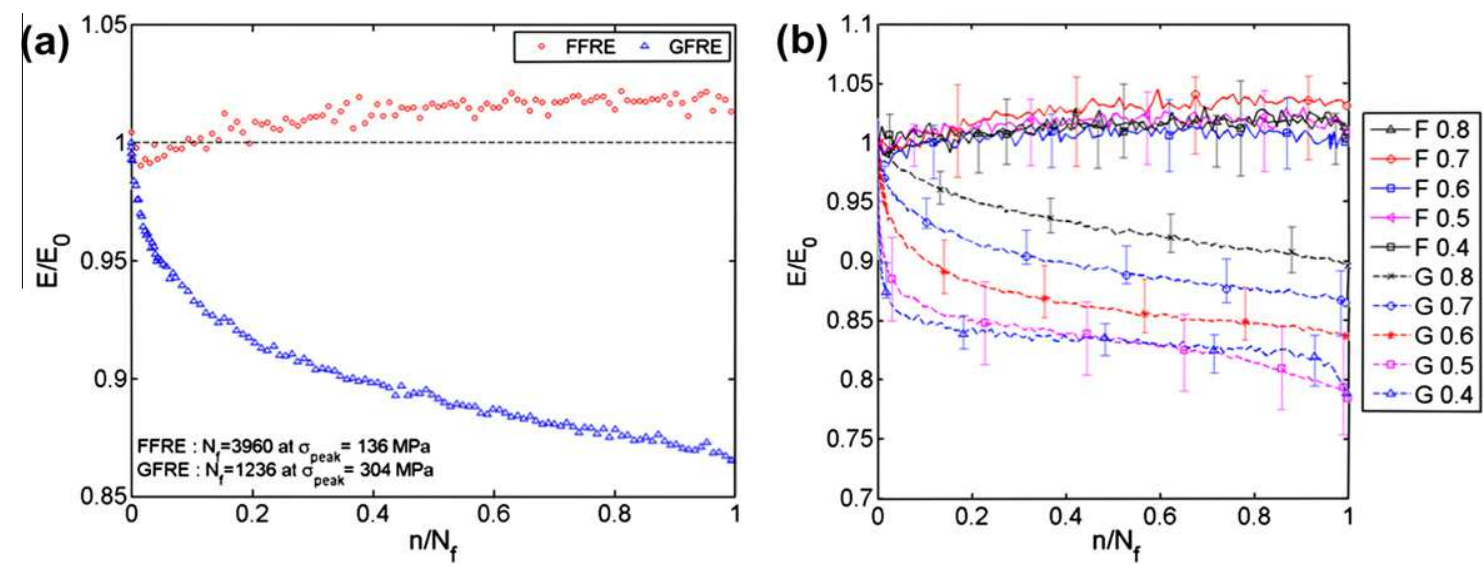

Fig. 12. Modulus ratio evolution of $[0 / 90]_{3 S}$ FFRE and GFRE specimens: (a) typical at 0.8 UTS and (b) global.
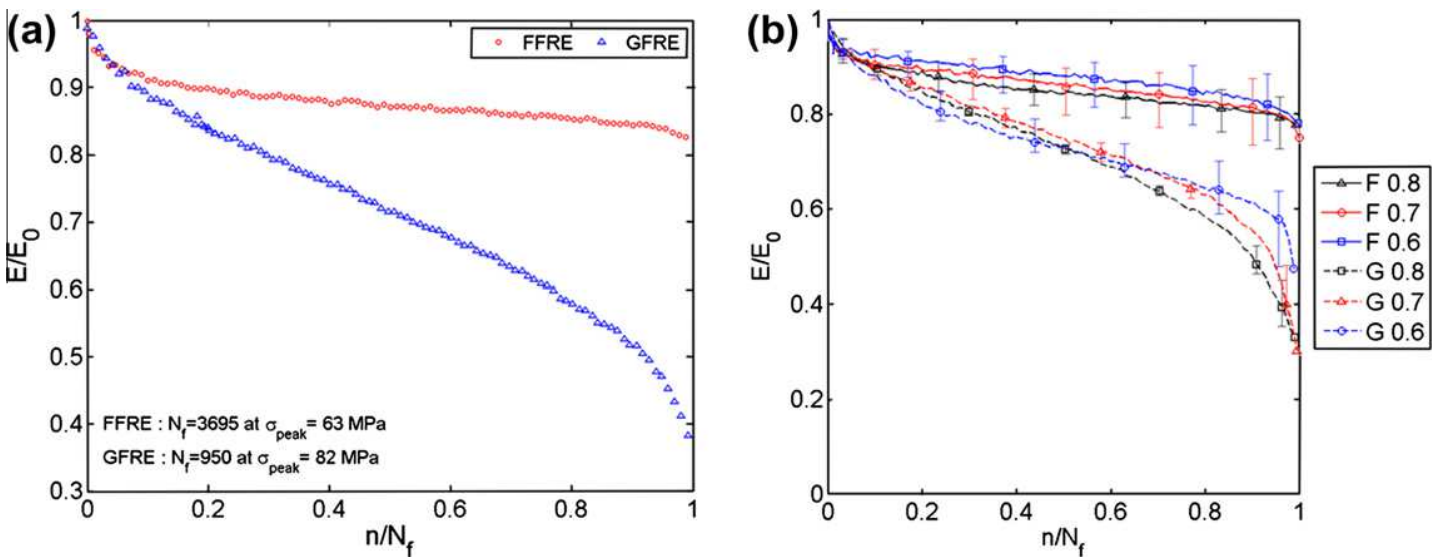

Fig. 13. Modulus ratio evolution of $[ \pm 45]_{3 S}$ FFRE and GFRE specimens: (a) typical at 0.8 UTS and (b) global (0.4-0.8 UTS).

straightening hypotheses can be partially confirmed by the permanent deformation described in Section 3.3.3. However, the slight stiffening phenomenon measured on composite scale is much less pronounced than that on fibre scale. The presence of fibres perpendicular to the load and the resin properties under fatigue loading may pull down the specimen's modulus.

Typical and global evolutions of the $E / E_{0}$ with respect to $n / N_{f}$ for $[ \pm 45]_{3 S}$ GFRE and FFRE specimens are plotted in Fig. 13 . The specimens' modulus decreases clearly in three stages as usually describe for composite materials. A steep decrease of the modulus happens in the early stages of the relative fatigue life, followed by the second steady decrease phase lasting for a relatively long life ratio, i.e. $0.1<n / N_{f}<0.9$. Thirdly, an acceleration stage occurs with an overall modulus loss of $15-20 \%$ for FFRE and of $50-70 \%$, for GFRE. GFRE samples' loss of modulus is more than three times higher than for FFRE ones. This points out that flax reinforced laminates present a more stable cyclic performance than the glass fibre reinforced ones. One can also conclude that for $[ \pm 45]_{3 s}$ FFRE and GFRE specimens the evolution of the stiffness is independent of the loading level.

\section{Conclusion}

Experimental investigations of fatigue tests have been conducted on FFRE and GFRE specimens with $[0 / 90]_{3 s}$ and $[ \pm 45]_{35}$ stacking sequences. Thermographic studies using the response surface method have suggested a test frequency of $5 \mathrm{~Hz}$ as a trade-off between temperature elevation and test duration. $S-N$ curves of
$[0 / 90]_{3 S}$ specimens show higher fatigue properties of the GFRE composites compared to FFRE. For $[ \pm 45]_{3 S}$ specimens, the fatigue resistance of GFRE is better than FFRE for stress levels higher than $64 \mathrm{MPa}$ but comparable below this level. The comparison of the specific stress reveals that the FFRE composites have a better resistance through the studied range. This phenomenon is considered to be due to the matrix controlled behaviour in the $[ \pm 45]_{3 s}$ lay up sequence combined with the lower density of the flax reinforcement. The statistical distribution of FFRE specimens' loglife follows a normal distribution while the standard deviations tend to decrease with the decreasing loading level which is converse to the literature. The analysis of the minimum cycle strains highlights permanent cyclic deformations occurring for all tested specimens.

$[0 / 90]_{3 S}$ GFRE specimens show a total loss of the modulus of $7-25 \%$ depending on loading level. In contrast, a modulus increase of around $2 \%$ is remarkable for the $[0 / 90]_{35}$ FFRE composites subjected to fatigue loading. This stiffening phenomenon can be explained by the self-straightening effect of the flax fibre in association with the realignment of the microfibrils contained in the fibre. The total loss of modulus of $15-20 \%$ and $50-70 \%$, respectively, is found on $[ \pm 45]_{3 S}$ FFRE and GFRE specimens suggest that flax fibre reinforced composites offer a more stable cyclic performance than the glass fibre composite. The stiffness degradation of both composites exhibits no dependence on the loading level.

\section{Acknowledgement}

The financial support of the FABER fund from the Bourgogne Region, France is gratefully acknowledged. 


\section{References}

[1] Le Duigou A, Davies P, Baley C. Interfacial bonding of flax fiber/poly (L-lactide) bio-composites. Comp Sci Tech 2010;70:231-9.

[2] Corbière-Nicollier T, Gfeller Laban B, Lundquist L, Leterrier Y, Manson JAE Jolliet 0 . Life cycle assessment of biofibres replacing glass fibres as reinforcement in plastics. Res, Conserv Recycl 2001;33:267-87.

[3] Bodros E, Pillin I, Montrelay N, Baley C. Could biopolymers reinforced by randomly scattered flax fibre be used in structural applications? Comp Sci Technol 2007;67:462-70.

[4] Gning PB, Liang S, Guillaumat L, Pui WJ. Influence of process and test parameters on the mechanical properties of flax/epoxy composites using response surface methodology. J Mat Sci 2011;46:6801-11.

[5] Charlet K, Baley C, Morvan C, Jernot JP, Gomina M, Bréard J. Characteristics of Hermès flax fibres as a function of their location in the stem and properties of the derived unidirectional composites. Composites: Part A 2007;38:1912-21.

[6] Baley C. Analysis of the flax fibres tensile behaviour and analysis of the tensile stiffness increase. Compos: Part A 2002;33:939-94.

[7] Placet V. Characterization of the thermo-mechanical behaviour of Hemp fibres intended for the manufacturing of high performance composites. Composites: Part A 2009;40:1111-8.

[8] Tong Y, Isaac DH. Impact and fatigue behaviour of hemp fibre composites. Compos Sci Technol 2007;67:3300-7.

[9] Silva FA, Chawla N, Filho RDT. An experimental investigation of the fatigue behavior of sisal fibers. Mat Sci Eng A 2009;516:90-5.

[10] Towo AN, Ansell MP. Fatigue evaluation and dynamic mechanical thermal analysis of sisal fibre-thermosetting resin composites. Comp Sci Techno 2008;68:925-32.
[11] ASTM D 3171-99. Standard test methods for constituent content of comp mater.

[12] ISO 13003, Fibre-reinforced plastic - determination of fatigue properties under cyclic loading conditions, 2003.

[13] Doehlert DH. Uniform shell designs. Appl Stat 1970;19:231-9.

[14] Doehlert DH, Klee VL. Experimental designs through level reduction of the ddimensional cuboctahedron. Discr Math 1972;2:309-34.

[15] A 03-405, Traitement statistique des données. 1991.

[16] Rabbe P, Lieurade HP, Galtier A. Essais de fatigue: partie I. Techniques de l'Ingénieur, traité Matériaux métalliques. M4170: 1-22.

[17] Case SW, Reifsnider KL. Fatigue of composite materials. Comprehens Struct Int 2003:405-41 [Chapter 4.16].

[18] De Monte M, Moosbrugger E, Quaresimin M. Influence of temperature and thickness on the off-axis behaviour of short glass fibre reinforced polyamide 6.6 - cyclic loading. Composites: Part A 2010;41:1368-79.

[19] Greco A, Musardo C, Maffezzoli A. Flexural creep behaviour of PP matrix woven composite. Compos Sci Technol 2007;67:1148-58.

[20] Vallons K, Zong M, Lomov SV, Verpoest I. Carbon composites based on multiaxial multi-ply stitched preforms - Part 6 . Fatigue behaviour at low loads: Stiffness degradation and damage development. Composites: Part A 2007;38:1633-45.

[21] Petermann J, Schulte K. The effects of creep and fatigue stress ratio on the longterm behaviour of angle-ply CFRP. Compos Struct 2002;57:205-10.

[22] Plumtree A, Melo M, Dahl J. Damage evolution in a [ \pm 45$]$ 2S CFRP laminate under block loading conditions. Int J Fatigue 2010;32:139-45. 